\title{
ADMINISTRAÇÃO FINANCEIRA
}

\section{Reestruturação das Repartições Aduaneiras}

\author{
Paulo Coriolano Tunis Viana
}

$\mathrm{D}$

ENTRE as repartições que compõem o aparelho arrecadador do Ministério da Fazenda, talvez sejam as Alfândegas e demais órgãos congêneres, os que mais necessitam da atenção dos legisladores e dirigentes da administração fazendária, no sentido de lhes dar estruturação adequada, de modo que possam ter um funcionamento satisfatório, condizente com a importância de que se revestem para a economia nacional, em face das atribuições que a legislação fiscal thes confere.

A arrecadação dos impostos de importação e de navegação, bem assim dos impostos internos de que se acham incumbidas por lei e regulamentos; os serviços de repressão e apreensão de contrabando; o policiamento fiscal dos mares territoriais, costas, tios, lagos e águas interiores. assim também das fronteiras terrestres, ancoradouros, portos, cais, docas; a fiscalização de aeroportos, entrepostos, armazéns e trapiches alfandegados; eis algumas das principais funções próprias das repartições aduaneiras.

Dessas repartições pertencentes à Diretoria das Rendas Aduaneiras, as mais importantes são as Alfândegas, que são localizadas nas Capitais e grandes Cidades situadas ao longo da costa marítima e zonas fronteiriças, às quais se subordinam as Mesas de Renda, Agências e Postos Aduaneiros, Estações Aduaneiras de Importação Aérea e Registros Fiscais, que são órgãos de maior porte.

A atividade das Alfândegas e órgãos correlatos se realiza através de serviços internos e externos, devidamente disciplinados por uma condensação de normas, denominada "Nova Consolidação das Leis das Alfândegas e Mesas de Rendas", que data do último decênio do século XIX, cujos setenta anos, quase, de existência, testemunham a justeza de tais normas, que estabelecidas para a época dos barcos a vela, atravessam galhardamente a era dos aviões a jato, como assinala o autor Antônio CAmpos, no prefácio de sua obra, em que comenta êsse diploma legal.

Consoante as atribuições legais das Alfândegas, observa-se que estas, através de seus múltiplos encargos, exercem dupla 
função: a de órgão que executa os serviços de arrecadação, de capatazia, fiscalização e policiamento externos; e, ainda, o de órgão controlador de outras repartições menores, que realizam, na sua maioria, os mesmos serviços, em escala reduzida.

Dois são os fatôres que, a nosso ver. mais concorrem para dificultar o bom funcionamento dêsses órgãos fazendários, em virtude do grande volume de serviço que acarretam decorrendo um dêles, da amplitude do território nacional, fazendo com que a extensão de cêrca de oito mil e quinhentos quilômetros de costa marítima e de dezesseis mil quatrocentos e vinte e três de linha fronteiriça terrestre, constitua, por si só, um permanente desafio à eficiência de tais órgãos, que têm a seu encargo, como dissemos além de outros serviços, o de exercer a viqialância fiscal em tôda a extensão dessa faixa territorial; o outro fator provém de incremento que nestes últimos tempos tem tido a aviação comercial no nosso país, em intercâmbio cada vez mais intenso com o exterior, dando origem à disseminação por todo o território nacional de grandes e pequenos aeroportos, muitos dos quais construidos, clandestinamente, em propriedades particulares, principalmente no sul do pais, para facilitar a entrada e saida de mercadorias contrabandeadas.

Segundo o critério que vimos preconizando, de algum tempo a esta parte, para a reestruturação dos órgãos arrecadadores do Ministério da Fazenda, a reforma das repartições aduaneiras, visando a torná-las mais eficientes, de modo a acompanhar o surto vertiginoso da importação e exportação, cujos tributos são por elas controlados e arrecadados, a reforma dessas repartições, diziamos, deveria processar-se tendo em vista a descentralização das funções de execução e centralização das de comando, regra que também aqui deveria ser aplicada juntamente com o principio da divisão de trabalho. Para o caso, a aplicação dêsses postulados compreenderá o desdobramento de cada setor administrativo ou executivo, tais como os acima referidos, de arrecadação de tributos, capatazias, fiscalização e política, em serviços tanto quanto possivel autônomos, mas coordenados entre si, significando, também, que deveriam ser criadas tantas repartições aduaneiras quantas fôssem necessárias à boa execução dos serviços respectivos, nos locais onde devem ser realizados, como por exemplo, com relação aos aeroportos situados nos centros econômicamente desenvolvidos do interior do país, cada um dos quais deveria possuir sua estação aduaneira própria, para contrôle da importação aérea, de mercadoria, que por êles transitem ou são
recebidas.

Por mais difícil que se apresenta o problema, não nos parece, no entanto, inexeqüivel a reestruturação das repartições adua- 
neiras, uma vez firmado o critério em que ela se deve apoiar, como vimos indicando com relação aos outros órgãos componentes do aparelho arrecadador do Ministério da Fazenda. Neste propósito, devemos apontar desde logo, uma medida de grande alcance para o disciplinamento dos serviços de arrecadação a cargo dessas repartições. Referimo-nos à atribuição a elas conferida, atualmente, de arrecadar, juntamente com os impostos de importação e navegação, também os impostos internos, quando o certo seria atribuir-lhes a arrecadação apenas dos primeiros, deixando os últimos a cargo exclusivamente das exatorias subordinadas, anteriormente, à Diretoria das Rendas Internas, hoje dependentes do Departamento de Arrecadação. Esta providência não só viria corrigir uma anomalia, como também traria o resultado imediato de desacumular os serviços das repartições aduaneiras, livrando as da tarefa estranha à sua finalidade. Além do mais, ocorre que parte da remuneração atual de grande número de funcionários fazendários, que não trabalham nas repartições aduaneiras, depois de quota calculada sôbre a arrecadação dos impostos internos, que, para o caso, não é computada quando feita através das repartições aduaneiras, cujos servidores se beneficiam, exclusivamente, dessa arrecadação, o que não é justo.

Com relação aos serviços denominados de capatazias, tais como direção e fiscalização do trabalho de descarga de mercadorias, conservação e segurança dos guindastes, armazéns, limpeza de páteos, dependências da repartição, recebimento de volumes descarregados nas pontes e cais, contrôle de armazenagem de mercadorias, etc., cremos não haver maiores dificuldades para as repartições aduaneiras, visto que a sua execução se acha sob a responsabilidade das administrações de portos, pelo menos nos de maior movimento, serviços êsses que estão, assim, naturalmente descentralizados.

Onde, porém, reside, a nosso ver, o ponto mais frágil da questão que estamos aqui focalizando, é nos setores pertinentes à fiscalização e polícia externas dos portos, ancoradouros, praias e, notadamente, os aeroportos, cujos serviços, como dissemos, se acham a cargo das repartições aduaneiras.

O contrabando, que se apresenta como um fantasma cada vez mais ameaçador, desafiando e - porque não dizê-lo desmoralizando autoridades e medidas postas em prática para reprimi-lo, ai está indicando a necessidade de uma cuidadosa reestruturação e reaparelhamento dêsses órgãos fazendários, em cujo âmbito de ação se verifica essa importuna irregularidade.

Observa-se, ûltimamente, um vivo interêsse dos podêres públicos, objetivado em dar combate a êsse incidioso mal, dados os 
efeitos danosos que êsse verdadeiro cancro produz no organismo nacional, exigindo, por isso mesmo, de todos os cidadãos, e, principalmente, dos que exercem função pública, uma colaboração assídua e organizada, a fim de extirpar o mal de maneira definitiva.

Entretanto, o «front" de combate a tão poderoso inimigo, tanto mais temivel quando se sabe que o comércio normal de algumas regiões do pais. mormente as lindeiras do extremo norte e sul do país, é constituído em grande parte, ou totalmente, de mercadorias em contravenção, com a conivência de autoridades locais, legalmente reconhecidas, essa frente repressora terá que ser organizada e comandada pelas repartições aduaneiras, por ser função específica a elas inerente.

Que nos conste, existe, presentemente, um Serviço de Repressão ao Contrabando, com sede na Cidade de Santa Maria, no Rio Grande do Sul, e com ramificações abrangendo as Cidades de Alegrete, Bagé, Cachoeira do Sul, Santo Ångelo, Cruz Alta, Rosário do Sul e São Gabriel, tendo o seû âmbito de ação resestender-se ao centro e norte do território nacional, devidamente articulados entre si, pois que o contrabando é semelhante ao polvo, cujos tentáculos surgem de tôda e em tôda parte, nesta nossa era eletrônica e do avião a jato.

Em certas circunstâncias o problema assume tal gravidade, que se torna indispensável o concurso até mesmo das Fôrças Armadas, especialmente a Aeronáutica e a Marinha, que por imperativo de defesa nacional, deverão prestar seu valioso auxílio às autoridades fazendárias incumbidas de zelar pelo cumprimento das leis fiscais. Outro não menos valioso auxílio poderá ser prestado pela polícia rodoviária e postos fiscais interestaduais ou "barreiras", através da fiscalização dos veiculos de transporte por estradas de rodagem.

Em seguimento à reestruturação dêsses órgãos fazendários, ou simultâneamente a ela, cumpre provê-los de pessoal escolhido e convenientemente treinado para exercer as arriscadas funções, próprias dêsses serviços de repressão à fraude fiscal, e dotá-los de meios rápidos de locomoção por terra, mar e ar, devidamente armados e equipados, de modo a poder sustentar uma guerra permanente contra os fraudadores da lei.

Para finalizar essas considerações, queremos nos referir a uma sugestão apresentada, certa feita, às superiores autoridades fazendárias, pelo autor destas linhas, quando chamado a se pronunciar sôbre o assunto, segundo a qual seria solicitada a cooperação dos exatores federais. no sentido de auxiliarem a campanha de 
repressão ao contrabando, recomendando-se-lhes exercessem, no âmbito de sua jurisdição fiscal, por si ou em colaboração com os demais órgãos fiscais da localidade onde estivessem servindo e sem prejuizo de suas funções principais, uma constante vigilância junto aos pontos de acesso de mercadorias em trânsito, tais como, estações ferroviárias e rodoviárias, agências de emprêsas de navegação aérea, onde se recebem ou despacham mercadorias, aeroportos, campos de pouso particulares, etc. A êsses servidores seriam conferidos, na ausência de órgãos especificos de fiscalização, plenos podêres para agirem com presteza e diligência, sempre que houvesse suspeita de irregularidade, quanto a mercadorias em contravenção, de tudo dando ciência imediata ao respectivo Delegado Fiscal e ao Diretor das Rendas Internas. Formar-se-ia, dêste modo, uma rede auxiliar de cêrca de duas mil coletorias federais, disseminadas por todo o território nacional, como uma sentinela vigilante, empenhada em preservar os legítimos interêsses da Fazenda Nacional, no caso especial da repressão ao contrabando. Tal sugestão, porém, por razões inconsistentes, foi rejeitada. 